\title{
LA FRAGILIDAD DEL SELF: ENSAYOS DE INTERVENCIÓN DE LOS UNTITLED FILM STILLS DE CINDY SHERMAN
}

\section{Lorena Muñoz Poveda ${ }^{1}$}

Este es un ensayo que se desprende de mi tesis de pregrado titulada "La fragilidad del self ${ }^{2}$. Pensando con los Untitled Film Stills de Cindy Sherman", defendida en el mes de septiembre del 2018 para optar por el título de historiadora en la Pontificia Universidad Javeriana. Las imágenes que conforman la serie fotográfica Untitled Film Stills (1977 1980) de Cindy Sherman tiene en su estética un aire al cine noir, art-house, al cine de directores como Renoir, Hitchcock, Rosellini, Antonioni y Vadim y a la imagerie de íconos como Marilyn Monroe, Audrey Hepburn, Brigitte Bardot y Sophia Loren. Esta suerte de mitología femenina contemporánea se construye previamente a la tormenta social y política que significó la década de los 70 en Estados Unidos. Junto a esta mitología, se instaura, a su vez, una dictadura del glamour que impondría unas formas del ser femenino y le otorgaría a lo femenino un valor de producto mercantil en plena era de la globalización. Untitled Film Stills resulta un mapa ficcional en torno a las femineidades de la postguerra, un archipiélago de yoes que se encuentra poblado de arquetipos fácilmente reconocibles: "Blonde victim", "Film starlet", "Fashion model", "Librarian", "Housewife", "Femme fatale", "Working girl”, "Seductress", "Murder victim", "Hillbilly girl”, "Tomboy", "Wonder woman" y "Girl-next-door". Sherman toma escenarios icónicos de Occidente y propone recorridos alternativos a la manera en que lo hacen las intervenciones y los montajes aquí expuestas.

Estas imágenes parecen atemporales y suspendidas, parecen estar siempre a la mitad de una acción, provocan una ilusión, una atracción y, al mismo tiempo, una repulsión incompresible para el espectador. Las imágenes parecen incompletas, parecen dar cuenta de un proceso irresuelto; se constituyen como abiertas y plurales. Estas imágenes evidencian identidades fracturadas, diluidas, abyectas $\mathrm{y}$, por parte del trabajo de apropiación de

\footnotetext{
${ }^{1}$ Pontificia Universidad Javeriana, Colombia. Email: lore munoz12@hotmail.com ORCID id: https://orcid.org/0000-0002-1480-6422

${ }^{2}$ Aquí se entiende el concepto de self como un camino intermedio entre el ser universal y el yo individual.
} 
Sherman, mutables.

En ellas, el sujeto va y viene, oscila pendularmente entre lo falso y lo real; asume roles constantemente, los apropia para luego abandonarlos, los resignifica y los reconstruye.

Estas fotografías a blanco y negro nos hacen testigos de femineidades que se fracturan y se escinden: personajes solitarios, expresiones vacías, gestos traumáticos, ensimismamiento, ansiedad, decoro, sensaciones de ausencia y de distancia y miradas profundas y perdidas en un más allá de la cámara. Aquí el vestuario, el maquillaje, la mirada, la pose y el gesto lo son todo. A pesar de que las mujeres parecen impenetrables y dan la sensación de estar anestesiadas, la cámara entra a hurtadillas, como una intrusa, en la intimidad de estas mujeres sorprendidas, la cámara las atrapa en la privacidad, sumidas en la reflexión y en la contemplación. La cámara es un voyeur y Sherman explora con ella tanto espacios domésticos y privados como públicos.

Sherman utiliza arquetipos, esencialmente artificiales, como una manera de resaltar esa artificialidad con la que se construyen. Por lo tanto, aquí propongo una mirada polivalente y variable del sujeto; una comprensión rizomática de él, como un conjunto de conexiones sin jerarquía, sin un principio y sin un fin, siempre en el medio, en intersección, incompleto, a la espera de algo y en constante cambio. Una mirada que pretende quebrar esa idea de sujeto como una verdad absoluta, como una entidad fija e inmutable; no habría identidades permanentes, sino sujetos plurales y variables. El sujeto moderno tal y como lo conocemos es frágil, su comprensión del ser como algo único e invariable es débil y poco precisa. Considero importante, entonces, problematizar a los sujetos que se presentan en esta serie a través de un mismo cuerpo, el de Sherman. El cuerpo sería, entonces, un espacio de lucha y lugar de subversión, ya que sobre él se ejercen mecanismos disciplinarios y prácticas normalizadoras que buscan encerrarlo en categorías y encasillamientos que no alcanzan a abarcar su complejidad.

Esta constante mascarada que Sherman ejerce sobre sí y sobre su cuerpo tiene la tarea de dinamitar unas concepciones unitarias y fijas del self; como lo hacen, por ejemplo, las practicas drag y el travestismo, los cuales, a través de su potencial crítico, evidencian la construcción artificial del sujeto. Por su parte, es interesante llamar la atención sobre los orígenes del concepto "persona": del latín persona traduce "mascarada del actor", lo cual alude a un self que se construye desde la artificialidad y que se permite residir distintas 
subjetividades, como una constante superposición de máscaras.

Por otra parte, la otredad es vital en esa construcción del yo, ya que, a su vez, este se construiría desde lo opuesto y desde lo que no es; aquí la diferencia, como lo plantea Derrida, produce significados y construye sentidos. Sin embargo, esa otredad no es homogénea, como muchas veces se quiere hacer creer: como una forma de reducir a quien se considera inferior; la otredad encierra una gran variedad de subjetividades que se construyen desde la exclusión, debido a que no tienen espacio dentro de un orden establecido por los ejes de poder. Es precisamente el reconocimiento de esa otredad, el que descentraliza esos cánones y regímenes de verdad y, a su vez, permite su pluralización y dinamización.

Esa otredad es múltiple, variable e inestable y se manifiesta en los siguientes fenómenos: la apropiación, la auto-ficción y la creación de alter-egos; este turismo de identidades es propio de la era de la globalización, de los mass media y de un mundo sumergido en una crisis constante. Un mundo en crisis que ha devenido en una descomposición social $\mathrm{y}$ en una crisis del sujeto, tanto identitaria como de la representación; esa crisis ha devenido en una fractura y en una fragmentación del self, el cual, por su parte, ha exigido una reformulación y resignificación. Un mundo en el que el self ya no es inmutable y no da muestras de estar acabado, sino que, por lo contrario, es una entidad in fieri, un self que se encuentra en proceso de ser desarrollado y en el que son posibles una multiplicidad de subjetividades.

Para estas ideas de los sujetos y los cuerpos móviles, el "Cuerpo sin Órganos” de Deleuze y Guattari es vital, ya que precisamente aborda al cuerpo desde su capacidad para transitar y cambiar de significación; la comprensión de estos autores del sujeto a través de fragmentos y no de totalizaciones, es sumamente enriquecedora para la lectura que aquí se plantea de la obra de Sherman. Por otro lado, es importante pensar en lo cyborg y en su redefinición de los cuerpos y de las identidades; al quebrar la tecnología esa frontera entre lo natural y lo artificial (personas hibridas), quiebra también la idea de un sujeto y de un cuerpo único, universal y estático. Así es como los debates de la segunda mitad del S. XX han llevado a pensar una variedad de cuerpos posibles: protésico, antropomórfico, artificial, carnal, orgánico, abyecto y posthumano (cyborg). Estas reflexiones en torno al self puestas 
en relación con las fotografías de Sherman dan como resultado las intervenciones y los montajes finales, previamente presentados.

En cuanto a estas reflexiones en torno al sujeto, no hay duda de que allí la fotografía tiene un papel decisivo, ya que le abre al sujeto la posibilidad de autorreferencialidad, documentación y registro de su propia existencia, lo cual le permite pensarse desde una visualidad y una materialidad distintas. Asimismo, me atrevería a señalar, entonces, que ese cambio en la comprensión del yo estaría detonado, o al menos muy influenciado, por la aparición de la fotografía y de las posibilidades visuales y representativas que esta brindaba. Respecto a las intervenciones y montajes que realicé, estos pueden ser pensados tanto como una relectura de las imágenes de Sherman, como el resultado de un proceso en el que se planteó la posibilidad de pensar junto a las imágenes, jugar con ellas, enfrentarlas y relacionarlas. Un proceso que, a su vez, tenía como objetivo identificar las ausencias, las distancias y los fragmentos que las habitaban, así como también los nuevos espacios de significación que estos permitían. Estas intervenciones son una forma de pensar la cuestión del self en la imagen, jugar con el sujeto en ella, representar visualmente las infinitas posibilidades del self, su estado de tránsito y su carácter artificial.

Estas intervenciones y montajes tienen mucho más sentido si se piensa en lo que señala Bourriad en su texto Postproducción, en el que afirma que la contemporaneidad funciona a partir y a través de injertos, trasplantes y descontextualizaciones, los cuales se evidencian no solo en la idea del sujeto fragmentado, sino en la lectura e intervención que se propone aquí de la obra. Entiéndase estas intervenciones y montajes como una operación quirúrgica en la que se disecciona la imagen, se trasplantan y se injertan en ella pedazos de otras subjetividades. En algunas intervenciones parece no haber sujeto, sino espacios vacíos; las fotografías originales estaban desteñidas, borrosas, una era muy blanca y la otra tenía lugar en un cuarto con chimenea; no obstante, sí había sujetos. Mi intervención de estas imágenes pretendía disolver y disgregar al sujeto en la imagen, a la manera que se disuelve la idea moderna de sujeto, pensar su contingencia y su inestabilidad; a estas intervenciones las llamé Desvanecimientos 1 y 2. Asimismo, esta desaparición del sujeto revela su estado de transito; estos distintos personajes y la misma Sherman se manifiestan 
como aquellas identidades nómadas, planteadas por Deleuze y Guattari.

En otras intervenciones se ven espacios inmensos poblados de una variedad de figuras; las fotografías originales de estos espacios mostraban sujetos minúsculos perdidos en la inmensidad de un espacio. Estas intervenciones en específico buscaban una coexistencia de yoes, los personajes ya no se encuentran solos, sino que se ponen en relación, visibilizan la coexistencia de pluralidades que habitan al self; pluralidades que se encuentran, se enfrentan, se acechan y se alimentan una de la otra. Por otro lado, está la intervención del "Montaje de los rostros", cada uno de ellos extraídos de las imágenes de la serie, separados del resto de su cuerpo y del espacio como cuando se corta un cordón umbilical, los rostros se encuentran suspendidos en un fondo oscuro, en un vacío. Un espacio que permite poner en relación los distintos yoes que habitan la serie; todos son Sherman, pero al mismo tiempo no lo son. Cada personaje tiene un aire distinto, juega a ser alguien distinto; las emociones, los gestos faciales y las sensaciones son siempre distintas, además de los elementos artificiales evidentes: ropa, maquillaje y pelucas. Estas intervenciones visibilizan lo artificial en la construcción del self, la facilidad que se tiene para ser y dejar de ser.

Finalmente, está el "rostro fragmentado" (piénsese en lo cyborg) del self en la contemporaneidad y la multiplicidad de formas de ser que habitan al ser. Esta intervención muestra un rostro a la manera de un rompecabezas, conformado por las partes de cuatro rostros diferentes de stills diferentes. El rostro se ha presentado históricamente como universal; no obstante, este rostro fragmentado es opuesto, abyecto, diferente y anómalo, un rostro que escapa a la unidad discursiva del poder ("cultura de la castración"); es en lo diferente y desde lo diferente que se construye al sujeto múltiple. Así es como estos montajes e intervenciones hacen visibles los procesos de construcción identitaria. Todos los rostros son Cindy Sherman; pero ¿en realidad lo son? Sherman es todas y al mismo tiempo ninguna, así es como un alguien puede llegar a ser cualquiera. El proceso de construcción del self nunca se cierra, siempre queda abierto a la posibilidad, al cambio. 


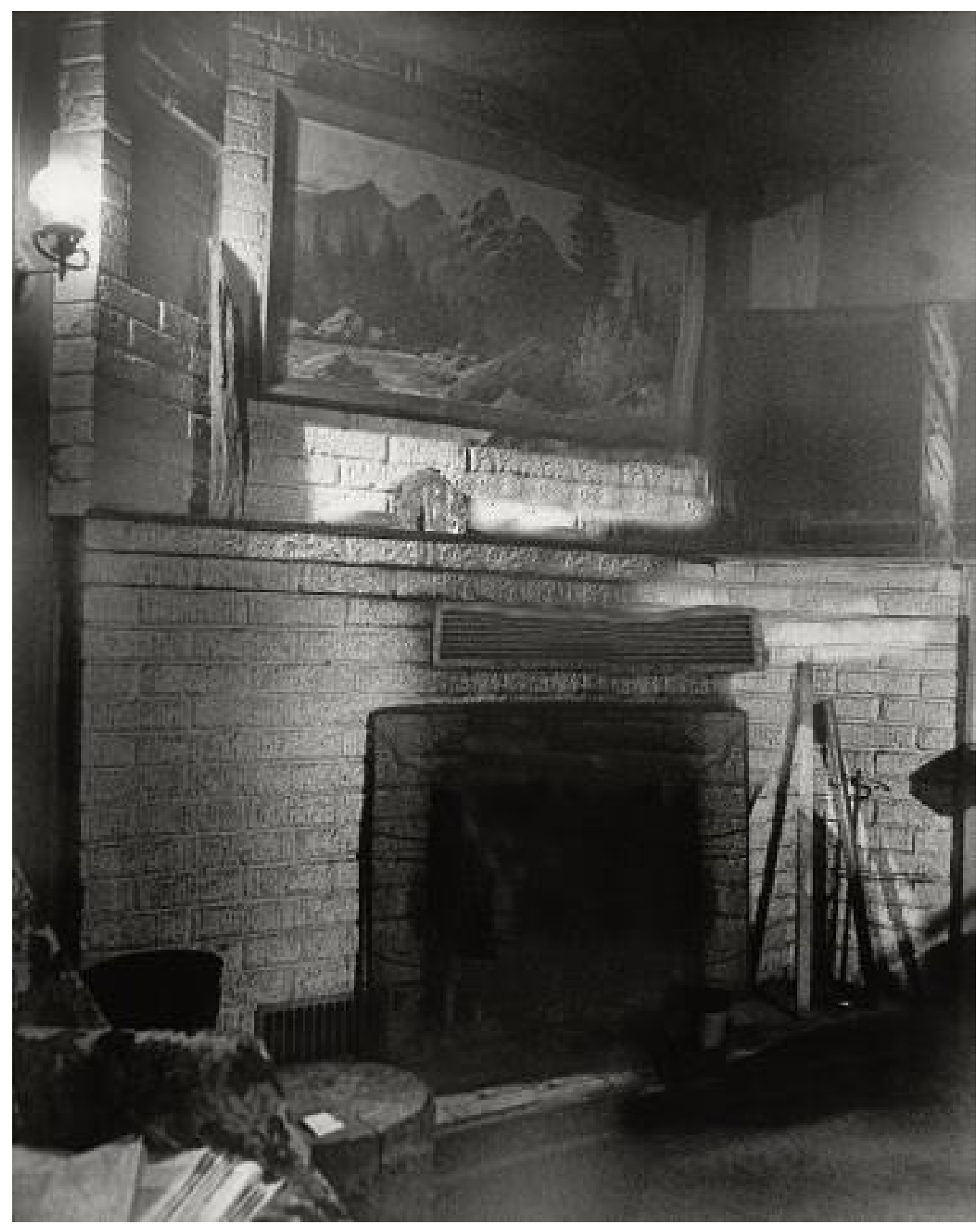

\section{Versión modificada}

Desvanecimiento 1

Untitled Film Stills \# 37

Cindy Sherman

1979

Museum of Modern Art, New York 


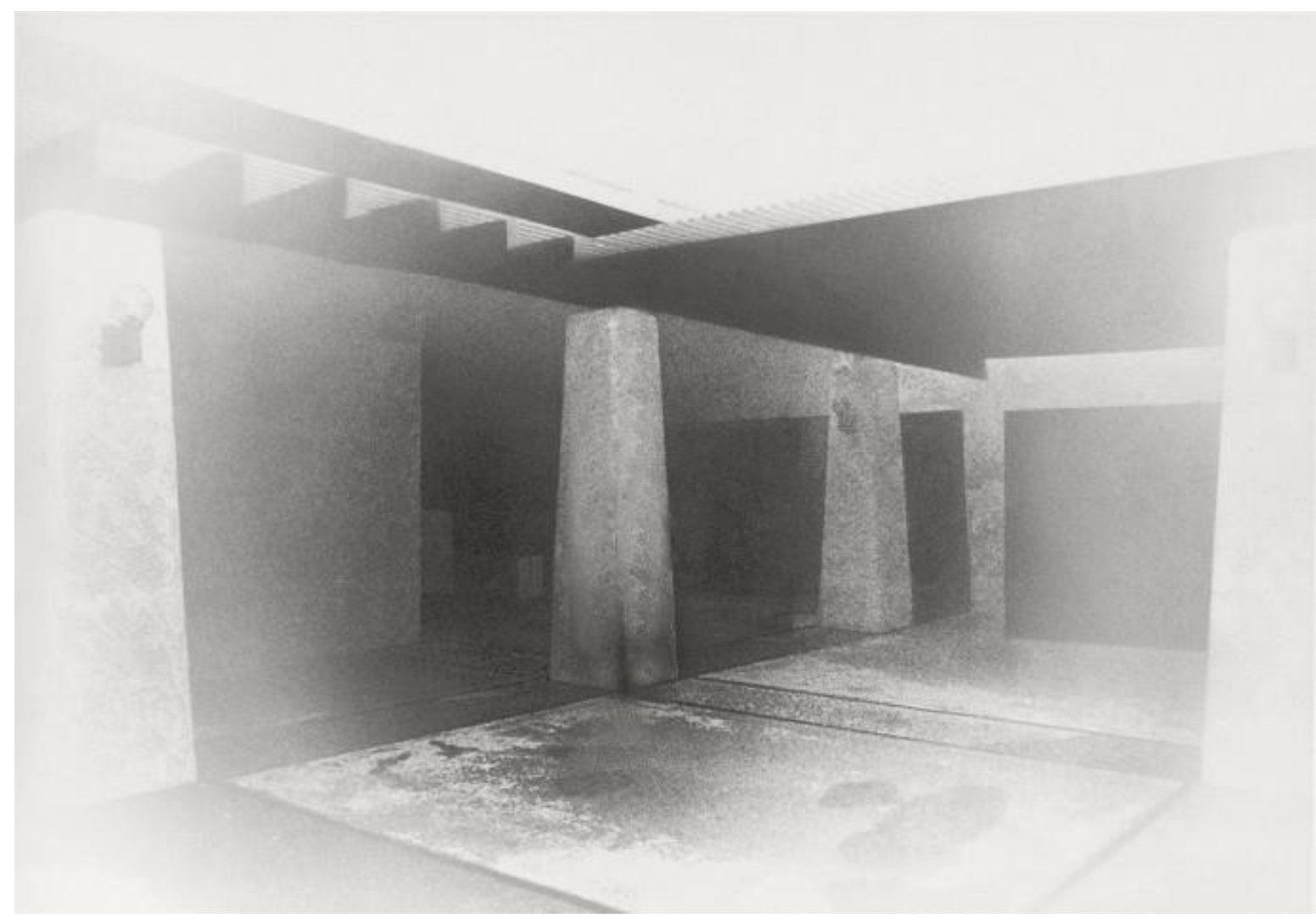

Versión modificada

Desvanecimiento 2

Untitled Film Still \#41

Cindy Sherman

1979

Museum of Modern Art, New York. 


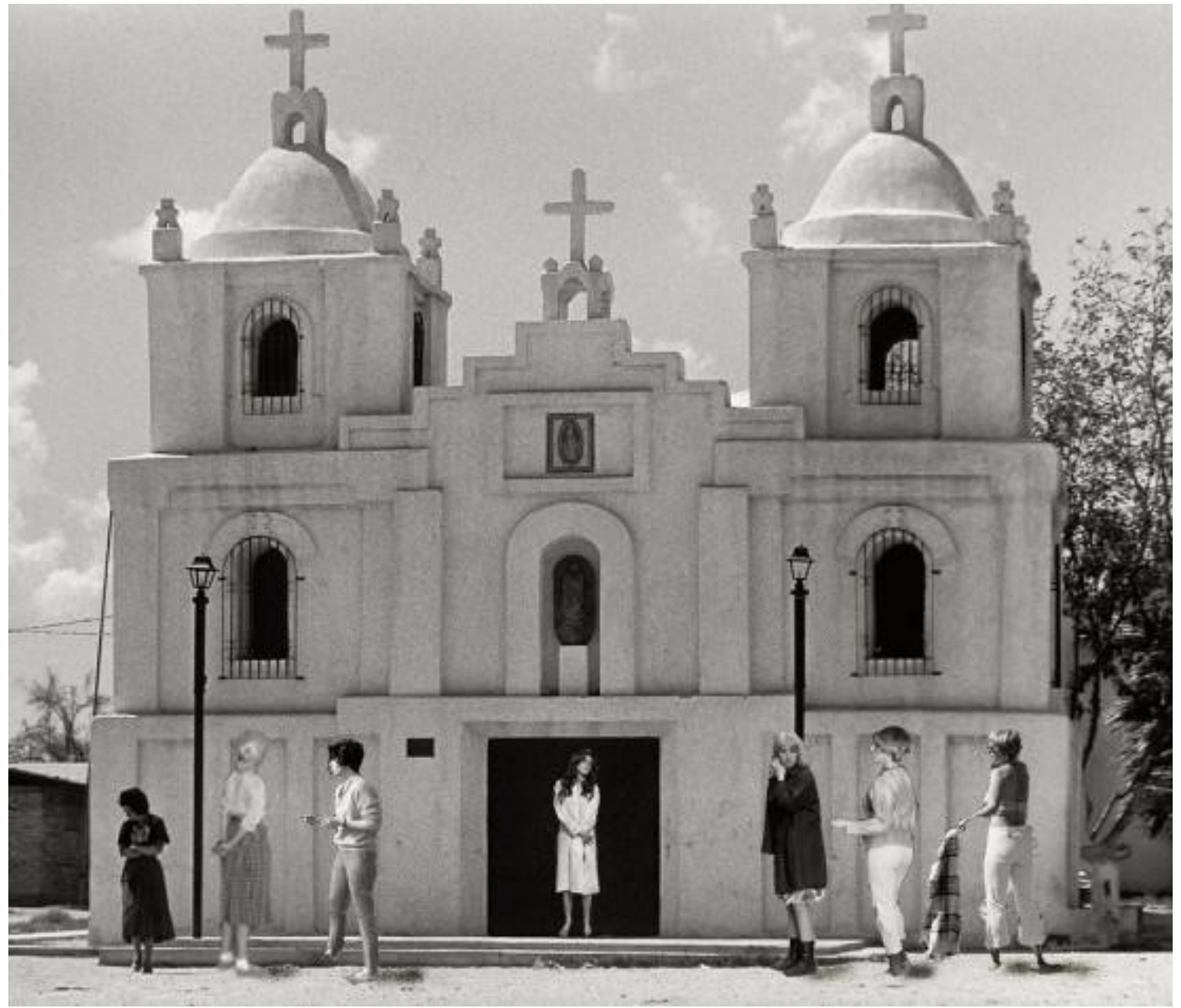

Versión modificada Uso de figuras de las UFS \#48, 60, 28, 63, 01, 08. Organizadas en ese orden numérico de izquierda a derecha. 


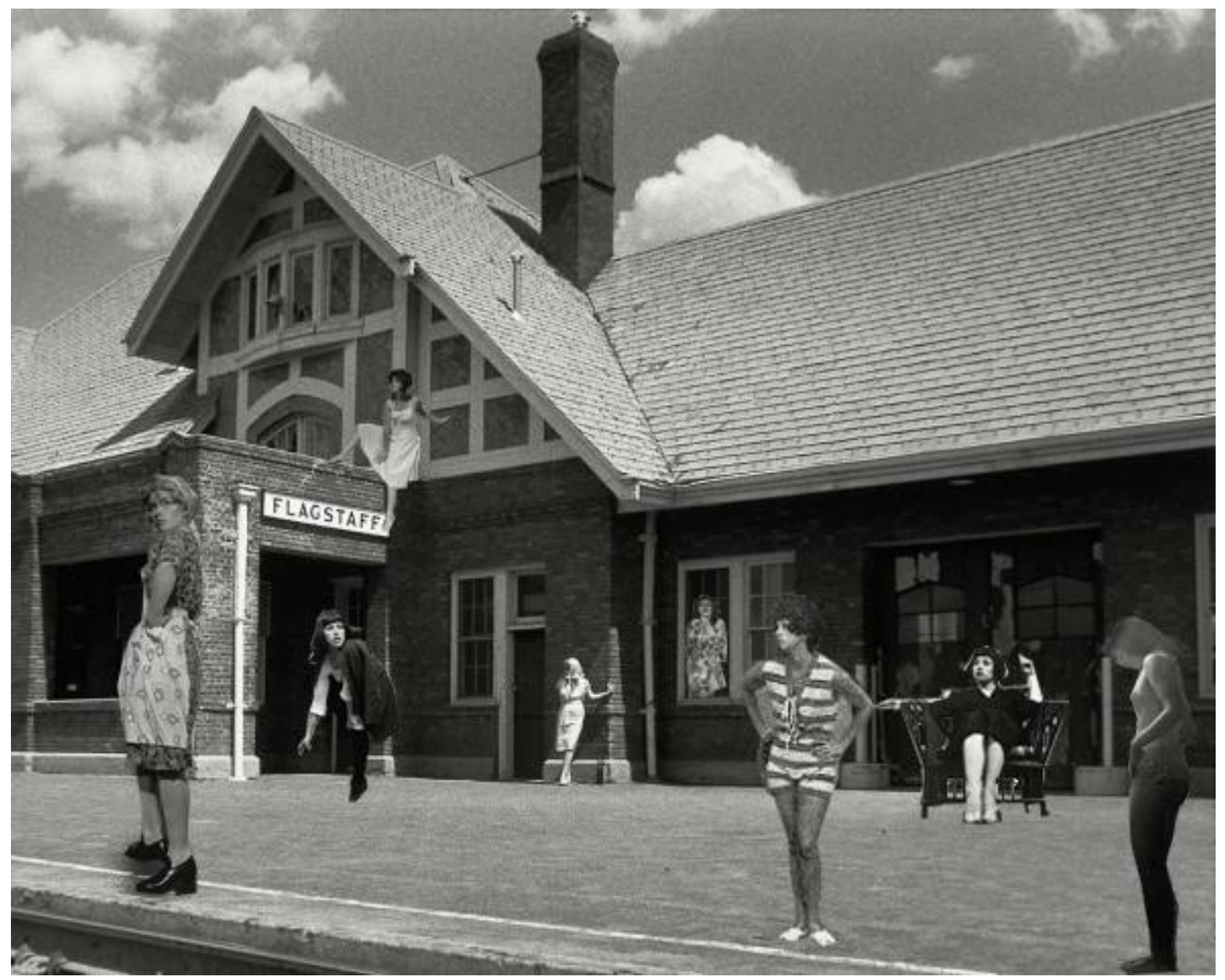

Versión modificada Uso de las figuras de las UFS 35, 43 (arriba), 84, 12, 41, 16, 39. Organizadas en ese orden numérico de izquierda a derecha. 


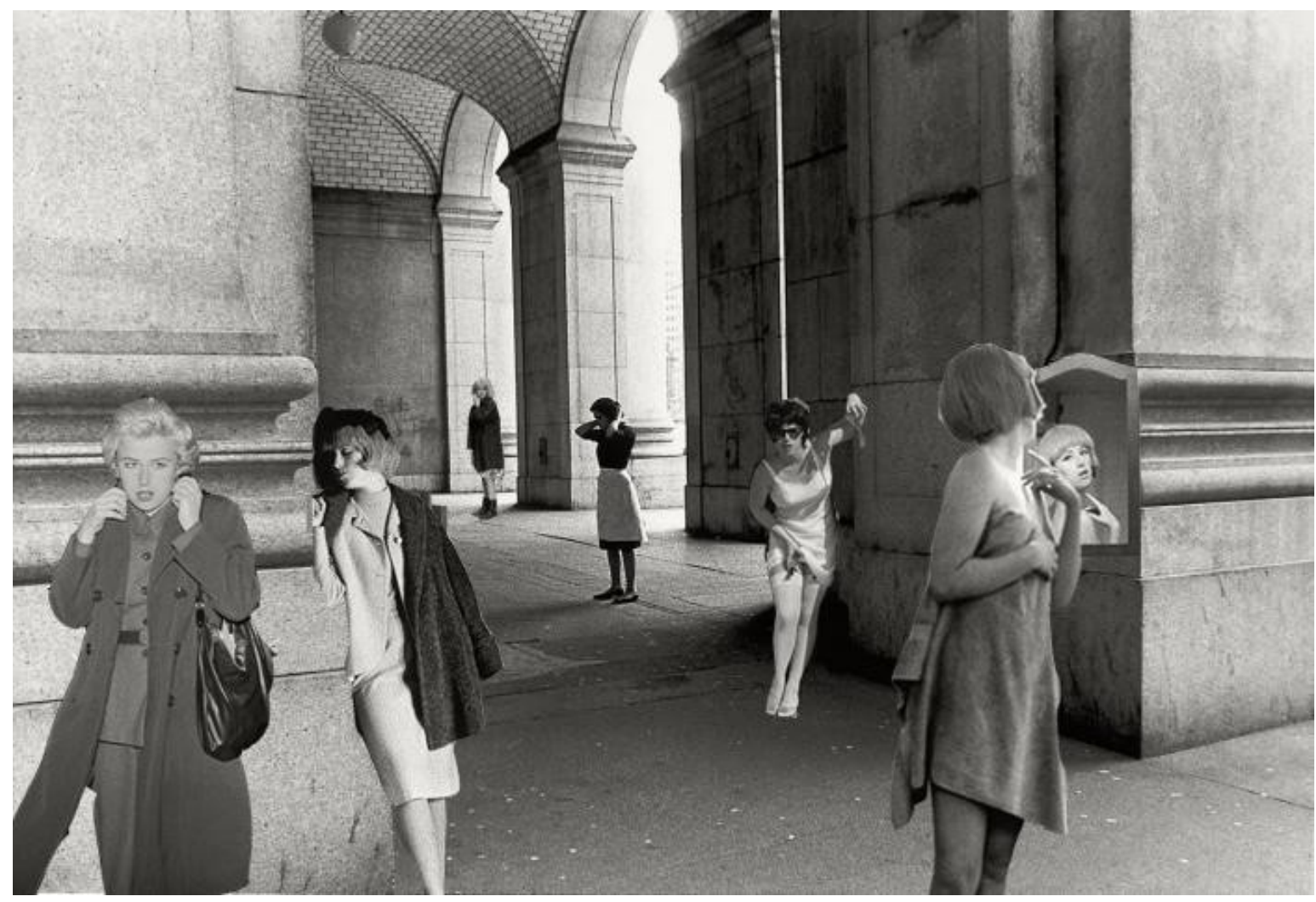

Versión modificada Uso de figuras de la UFS \#54, 04, 63, 07, 02. Organizadas en ese orden numérico de izquierda a derecha. 


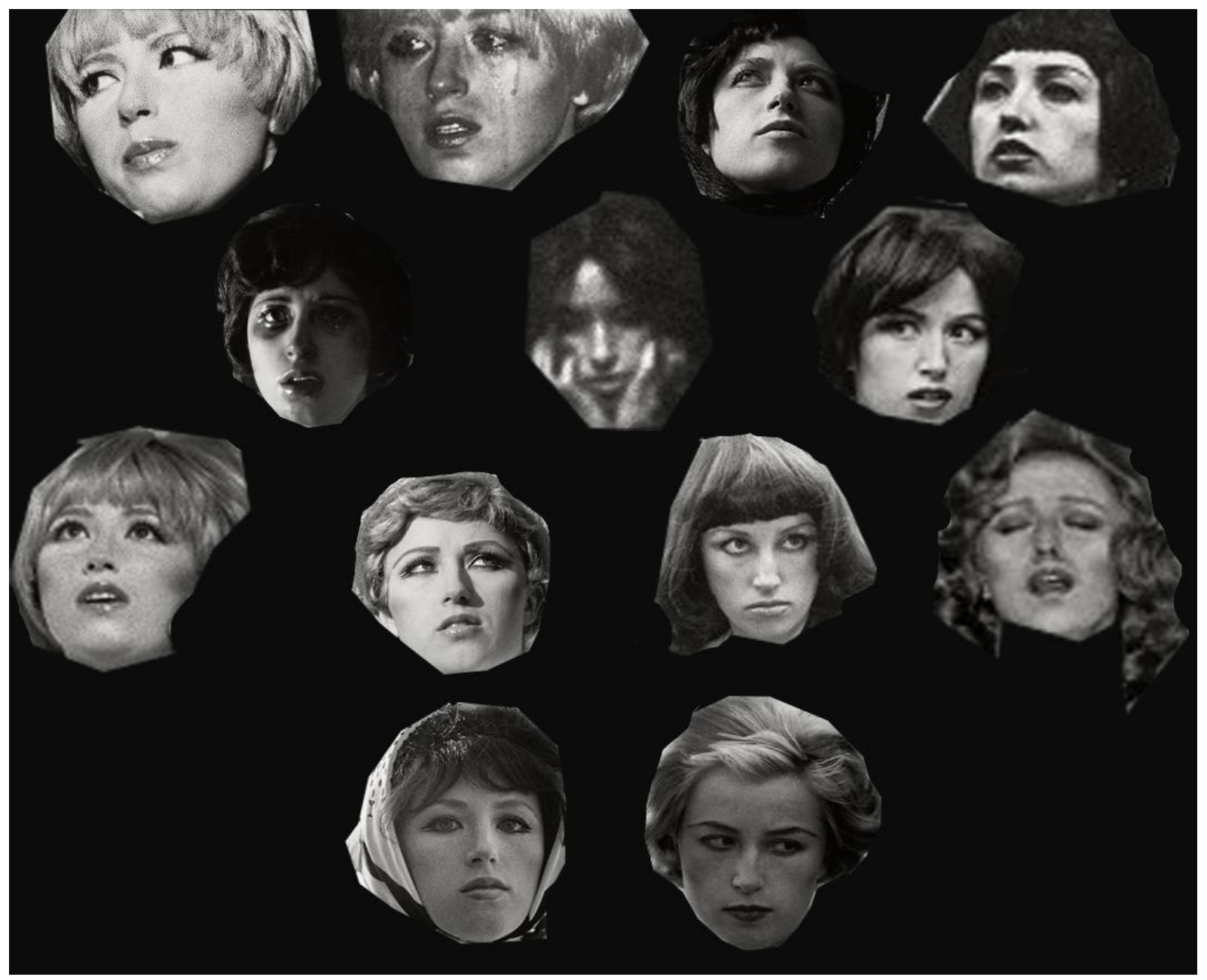

Montaje Rostros (UFS \#5, 27, 58, 16, 30, 26, 14, 06, 21, 10, 12, 17, 53): organizadas en ese orden numérico de izquierda a derecha, de arriba abajo. 


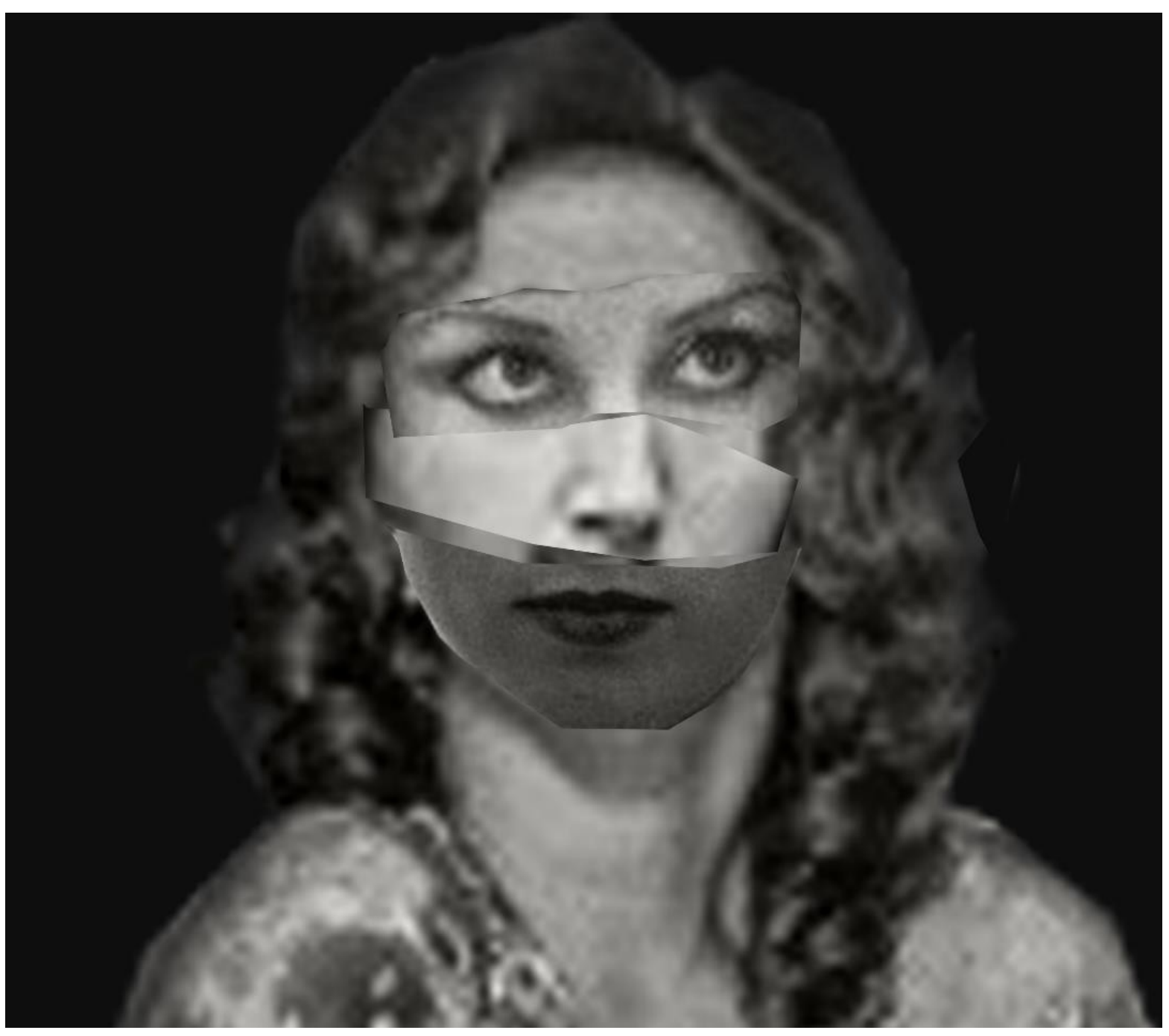

Montaje Rostro fragmentado (conformado por fragmentos de rostro de las UFS \#12, 10, 14, 53): Organizadas en ese orden numérico de arriba a abajo. 


\section{REFERENCIAS}

ASBERG, Cecilia. (2009). The arena of the body: the cyborg and feminist views on biology. En R. Buikema e I. van der Tuin (Eds.), Doing Gender in Media, Art and Culture. London: New York Routledge Taylor \& Francis Group.

BERGER, John. (2000). Usos de la fotografía. Elementos, 47 - 51. Recuperado de https://www.academia.edu/15224116/USOS_DE_LA_FOTOGRAF\%C3\%8DA. _JOHN_BERGER?auto=download.

BOURRIAUD, Nicolas. (2007). Postproducción. Buenos Aires: Adriana Hidalgo Editora.

CORTES, José M. (2004). Buceando en la identidad y el deseo. En P. A. Cruz Sanchez y M. A. Hernandez Navarro (Coords.), Cartografías del cuerpo: la dimensión corporal en el arte contemporáneo, (pp. 179- 194). España: Centro de Documentación y Estudios Avanzados de Arte Contemporáneo (CendeaC).

DELEUZE, Gilles y Guattari, Félix. Rizoma. Sin datos bibliográficos. . (1980). Conversaciones. Valencia: Pre-textos.

DELEUZE, Gilles y Parnet, Claire. (1980). Diálogos. Valencia: Pre-Textos.

DIDI-HUBERMAN, Georges. (2009). La imagen - síntoma. Fósiles en movimiento y montajes de memoria. En La imagen superviviente. Historia del arte y tiempo de los fantasmas según Aby Warburg (pp. 245 - 466). España: Abada Editores.

(2011). Ante el tiempo: Historia del arte y anacronismo de las imágenes.

Argentina: Adriana Hidalgo Editorial.

ESCUDERO, Jesús A. (diciembre, 2002). Cuerpo y transgresión: Cindy Sherman y la visión fotográfica de la mutación humana. Trabajo presentado en el seminario Tecnología y posthumanidad: la artificialidad del ser en la Universidad Autónoma de Barcelona, Barcelona, España.

ETCHEGARAY, Ricardo. El concepto deleuziano de cuerpo. Sin datos bibliográficos.

HARTNEY, Eleanor. (2013). Cindy Sherman: the polemics of play. En E. Hartney, H. Posner, N. Princenthal, S. Scott y L. Nochlin, Women who transformed contemporary art, (pp. 168 - 187). Munich, London, New York: Prestel. 
MORRIS, Catherine. (1999). The essential Cindy Sherman. New York: Harry N. Abrams Inc., Publishers.

MULVEY, Laura. (1991). A phantasmagoria of the female body: the work of Cindy Sherman. New Left Review.

PAGOTTO, María A. (2010). Gilles Deleuze y Félix Guattari: políticas del rostro. Ensayo presentado en la VI Jornada de Sociología de la UNLP, La Plata, Argentina.

PARDO SAINZ, Rebecca. (2012). "El otro yo. De la autoficción al turismo identitario en el arte contemporáneo". Revista Sans Soleil. Recuperado de http://revista- sanssoleil.com/wpcontent/uploads/2012/02/art-Rebeca-Pardo.pdf.

RACY, Gustavo. (2017). Walter Benjamin's Concept of the Image: the case of Photography. Critical Theory Research Network.

RESPINI, Eva. Will the real Cindy Sherman please stand up? Museum of Modern Art of New York. Recuperado de https://www.moma.org/momaorg/shared/pdfs/docs/learn/courses/Respini_Will_t he_Real_Cindy_Sherman_Please_Stand_Up.pdf.

VILELA, Eugénia. (2009). Bajo los vestigios de un Cuerpo: cultura, discurso y acontecimiento. Calle14 vol. 3. Recuperado de https://repositorioaberto.up.pt/bitstream/10216/39356/2/eugeniavilelabajo000112919.pdf

WOLFF, Francis. (2013). El poder de las imágenes. En Adauto Novaes (Org.), Muito Além do Espetáculo. São Paulo: SESC

Recebido: $10 / 02 / 2020$

Aprovado: $15 / 07 / 2020$ 